\title{
¿Contribuyeron los medios de comunicación al golpe de Estado? Otra historia del periodismo durante la Unidad Popular (1970-1973) ${ }^{*}$
}

\author{
Did media contribute to Chilean Coup d'Etat? \\ Another history of journalism during Popular Unity (1970-1973)
}

\begin{abstract}
Antoine Faure ${ }^{* *}$
Resumen: Frente a una memoria hegemónica que atribuye cierta responsabilidad a los periodistas en la instalación de las condiciones del golpe de Estado en Chile, ponemos en evidencia las continuidades del periodismo profesional chileno que rebaten la hipótesis de una ideologización univoca de la prensa escrita. A partir de una metodología mixta, analizamos las formas y materias de la prensa, archivos institucionales y entrevistas de periodistas que ejercieron durante la Unidad Popular (1970-1973). Se pone en evidencia un reajuste de las tareas periodísticas bajo la presión de la crisis política: la temporalidad periodística institucionalizada se desconfigura y aparecen nuevas lógicas en el quehacer periodístico (la prioridad por el flujo de noticias por encima del trabajo de puesta a la agenda).
\end{abstract}

Palabras clave: Periodismo, Crisis, Rutinas, Historicidad de los medios de comunicación.

\begin{abstract}
Journalism memory reminds the contribution of press in building 1973 Coup's atmosphere and conditions. Facing this hegemonic tale, we try to show the continuities in Chilean journalism, in order to wipe out the ideologization analysis. Through a mixed methodology, we analyze press' forms and materials, institutional archives and journalists' interviews. We see the development of several adjustments of journalistic tasks with the political crisis emergency: institutional journalistic temporality is dis-configuring and new temporal logic show up in the journalistic work (news' flow priority above agenda setting).
\end{abstract}

Keywords: Journalism, Crisis, Routines, Norms, Media's Historicity.

Recibido: 5 diciembre 2016

Aceptado: 23 marzo 2017

\footnotetext{
* Este artículo es parte de la tesis de doctorado titulada "Dés(-)ordres journalistiques dans une crise révolutionnaire. Chroniques de l'être journalistique chilien durant l'Unité populaire (1970-1973)", que fue dirigida por Olivier Ihl (Pr. de Ciencia política), financiada por el Ministerio de Enseñanza Superior e Investigación de Francia, y defendida el 8 de diciembre de 2014 en Sciences Po Grenoble. <http://www.theses.fr/s97161>. También reformula parte de los argumentos publicados en otro artículo de mi autoría publicado en francés, "Par temps agités. Temporalités journalistiques et crises politiques au Chili", Temporalités, $\mathrm{n}^{\circ} 23,2016$, <http://temporalites.revues.org/3352>.

** Nacionalidad francesa. Profesor-Investigador (en curso de jerarquización), Centro de Investigación y Documentación (CIDOC), Universidad Finis Terrae antoinelucienfaure@gmail.com
} 


\section{Una historia de la ideologización: la prensa durante la Unidad Popular}

En 1985 el sociólogo Patricio Dooner publicó uno de los primeros estudios hechos en el territorio nacional sobre el periodismo y la prensa durante la Unidad Popular (1970-1973) ${ }^{1}$. Varios textos se habían escrito sobre el problema desde afuera ${ }^{2}$, pero el régimen autoritario impedía una reflexión académica sobre esas materias en Chile. A pesar de lo inédito del estudio en ese contexto, lo interesante de ese dato editorial reside en el objeto de análisis: Patricio Dooner sólo consideraba la prensa de izquierda. Como si los medios de comunicación de derecha no hubieran tenido importancia durante el gobierno de Allende. Y como si la actividad de los medios de izquierda pudiera explicar el ejercicio transversal del periodismo durante el periodo. Este asunto lo admite el mismo autor en la "explicación al lector" de una segunda edición largamente complementada ${ }^{3}$ : esa "torpeza" fue rápidamente corregida dado que, durante la presentación del primer texto, el público le preguntó también por lo que ocurrió en el otro lado del escenario político.

Más allá de esa impericia, la mirada del sociólogo era sobre todo ideológica. Para entender la relación entre prensa y política en aquel entonces, Patricio Dooner partía del supuesto de que se debe estudiar la prensa de cada campo de la batalla política por separado. En cierta medida, ese enfoque muestra que la polarización política de la sociedad es un factor que antecede a todo tipo de estudio histórico del periodo, como si una politización extrema llevase la inestabilidad a todos los campos sociales de manera sistemática. En consecuencia, el autor analizó el periodismo durante la Unidad Popular (UP) a partir de las líneas editoriales, sin tomar en cuenta la complejidad de los diarios. Y mostraba las tendencias al maniqueísmo, la intolerancia y la vulgaridad que tomó el periodismo entre 1970 y 1973, marcando especificidades: la prensa de derecha se diferencia por llamar a la violencia y al golpe de Estado, mientras que el periodismo de izquierda sería

\footnotetext{
${ }^{1}$ Patricio Dooner, Periodismo y Política: la prensa de izquierda en Chile 1970-1973, ICHEH, Santiago de Chile, 1985.

2 Por orden cronológico, se encuentra principalmente: Patricia Fagen, "The Media in Allende's Chile", Journal of Communication, vol. 24, n²1, Winter 1974, pp. 59-70; Armand Mattelart, Mass media, idéologie et mouvement révolutionnaire : Chili 1970-1973, Paris, Anthropos, 1974 ; Juan Rojo de la Rosa, "Manipulación de información y conflicto ideológico: Chile 1970-1973”, Nueva Sociedad, julio-agosto 1976, Caracas; Armand Mattelart, Michèle Mattelart, Frentes culturales y Movilización de masas, Barcelona, Anagrama, 1977; Armand Mattelart, Michèle Mattelart, De l'usage des médias en temps de crise, Paris, Alain Moreau, 1979 ; Michèle Mattelart, Yvonne Mignot-Lefebvre, "Chili : formation politique et lecture critique de la télévision", Tiers Monde, vol. 20, n79, 1979, pp. 523-541; Hernán Uribe Ortega, "Los medios: armas de la guerra encubierta", Comunicación y dependencia en América Latina, Universidad Nacional Autónoma de México, México, 1979; Diego Portales, "El movimiento popular y las comunicaciones: reflexiones a partir de la experiencia chilena" en Fernando Reyes Matta, Comunicación alternativa y Búsquedas democráticas, México D. F., ILET, 1983. El mismo año que Patricio Dooner, Guillermo Sunkel publica su famoso libro inspirado por los Estudios Culturales: Guillermo Sunkel, Razón y Pasión en la Prensa Popular. Un Estudio sobre Cultura Popular, Cultura de Masas y Cultura Política. Santiago de Chile, Estudios ILET, 1985. Tres años más tarde, Eduardo Santa Cruz toca el periodo en el tercer capítulo de su libro clásico: Eduardo Santa Cruz A., Análisis histórico del periodismo chileno, Santiago de Chile, Nuestra América Ediciones, 1988.

3 Patricio Dooner, "Explicación al lector" en Periodismo y política. La prensa de derecha y de izquierda (1970-1973), Santiago de Chile, Editorial Andante y Hoy Ediciones, pp.13-15.
} 


\section{"totalitario"4.}

Ahora bien, el problema de la contribución de los medios de comunicación al golpe de Estado no sólo se formula en las décadas de los 70 y 80, lo que se podría explicar por el contexto del régimen cívico-militar. La tendencia se sedimenta y sobrevive durante la "transición democrática", entendida como periodo de la historia política chilena y a la vez como proyecto político refundacional. Varios textos clásicos, por lo menos en el campo de los estudios mediáticos, ocupan estrictamente las mismas palabras y las mismas bases empíricas. Lo más emblemático sería, sin duda, el artículo de Patricio Bernedo y William Porath publicado en 2004 en la revista de comunicaciones de la Pontificia Universidad Católica de Chile (PUC), y titulado: "A tres décadas: ¿Cómo contribuyó la prensa al quiebre de la democracia chilena?"5. De hecho, el relato se reactivó de manera sistemática para la conmemoración del 11 de septiembre ${ }^{6}$, o a través del mea culpa de los periodistas que ejercieron la profesión bajo el gobierno de Salvador Allende ${ }^{7}$.

\footnotetext{
${ }^{4}$ El uso de esa categoría es muy sorprendente dado el respecto de las garantías constitucionales de parte del gobierno de la Unidad Popular. En termino teórico, es claramente abusivo, que se entienda el "totalitarismo" como un periodo histórico (cf. Ian Kershaw, La dictadura nazi: problemas y perspectivas de interpretación, Buenos Aires, Siglo XXI, 2004) o que resulte como la desaparición de la frontera entre espacio público y espacio privado (ver Hannah Arendt, Los orígenes del totalitarismo, México, Taurus, 2004).

${ }^{5}$ Patricio Bernedo, William Porath, "A tres décadas del golpe: ¿Cómo contribuyó la prensa al quiebre de la democracia chilena?", Cuadernos de Información, n 16-17, 2004, PUC, pp. 114-124.

${ }^{6}$ Sólo citaremos aquí los textos a los que no nos hemos referido todavía: Patricio Bernedo, "La prensa escrita durante la Unidad Popular" in Claudio Rolle, 1973: La vida cotidiana en un año crucial, Santiago de Chile, Planeta, 2003, pp. 59-95; Alfredo Joignant, "Sens, masse et puissance. Dégradations cérémonielles et représentations de la puissance sous l'Unité populaire au Chili (1970-1973)" in Isabelle Sommier \& Xavier Criettez (dir.), Les dimensions émotionnelles du politique. Chemin de traverse avec Philippe Braud, Paris: Presses universitaires de Rennes, 2012, pp. 131-142; Eugenio Tironi, Guillermo Sunkel, "Modernización de las comunicaciones y democratización de la política. Los medios en la transición a la democracia en Chile", Estudios Públicos, n ${ }^{\circ}$ 2, primavera 1993, pp.215-246; Patricio Tupper, Allende, la cible. Des média chiliens et de la CIA (1970-1973), Paris, Editions de L'Amandier, 2003.

${ }^{7}$ En el programa "Secretos de la Historia" de canal 13, Hermógenes Pérez de Arce declara: "No desearía que se repitiera una prensa como la que tuvimos por ambas partes, gatillada por el estilo que inauguró Clarín y que después se vio reflejado en los diarios de oposición a la UP, que decían cosas iguales o peores. Creo que eso no le hizo bien al país. Yo creo que uno podía eventualmente entretenerse y reírse porque se publicaban cosas divertidas, pero a costa de la honra de las personas; o sea, eran personas que difícilmente podían salir a la calle después de estos titulares que aparecían. Se publicaban cosas abiertamente injuriosas y calumniosas de todo el mundo", citado en Bernedo, Porath, op. cit, p. 124. En la misma perspectiva, se publicaron varios textos: Lidia Baltra M., La prensa chilena encrucijada. Entre la voz monocorde y la revolución digital, Santiago de Chile, LOM Ediciones / CYP/CH, Colección "Ciencias humanas", 2012; Juan Pablo Cárdenas, "Periodistas, conflictos sociales y reconciliación", Revista Comunicación y Medios, $\mathrm{n}^{\circ} 16$, Instituto de Comunicación e Imagen, Universidad de Chile, 2005,

<http://www.revistas.uchile.cl/index.php/RCM/article/viewFile/11567/11925> (consultado el 17 de enero de 2012); Toño Freire, "Con "Clarín" y "Puro Chile" temblaba "El Mercurio" y "La Tercera", Centro de estudios Miguel Enríquez - Archivo Chile, 2005,

<http://www.archivochile.com/Experiencias/exp_popu/EXPpopulares0030.pdf> (consultado el 23 de mayo de 2008); Arturo Navarro Ceardi, "La prensa chilena en termino de Cólera", 05 de noviembre 2013, <http://arturo-navarro.blogspot.fr/2013/11/la-prensa-chilena-en-tiempos-de-colera.html> (consultado el 6 de noviembre de 2013); Abraham Santibañez, "Presentación” en Dooner, op. Cit., 1989.
} 
En síntesis, esos estudios ven una contribución indirecta de los periodistas al golpe de Estado, dado que no son ellos quienes lo implementaron, sino que habrían instalado las condiciones de polarización y agudización del conflicto. Esa mirada articula dos argumentos. Primero, se constata la polarización editorial del mercado mediático y segundo, se estudia los mensajes desde el filtro de la batalla política. Mientras que en el mismo momento de los hechos se analizaba la ideología que circulaba en la prensa bajo el sesgo de la objetividad periodística ${ }^{8}$, los investigadores hacen, desde 1973, el estudio de la ideologización de los medios de comunicación que llevaría al golpe de Estado. Como si el resultado explicara el desarrollo anterior", y que "todo sólo pudiera pasar como pasó efectivamente, olvidando las incertidumbres y contingencias propias del periodo, incluso los posibles no sucedidos"10. Esa tendencia resulta sospechosa, dado que cierra todas las posibilidades históricas, los proyectos abortados, como si la Historia fuera lineal y mecánica. Más suspicaz aún, ese relato converge con el mismo discurso de legitimación de la Junta Militar, que presentó su irrupción violenta en el transcurso de la democracia para proteger del caos la unidad del país.

El relato dominante en los estudios sobre el tema se adscribe, entonces, a la tesis de la agudización del conflicto que desborda las instituciones ${ }^{11}$ y provoca la ruptura del centro político regulador del Estado de compromiso ${ }^{12}$. En otras palabras, los periodistas, la prensa y los medios de comunicación en general habrían vuelto, entre 1970-1973, a un periodismo doctrinario que remite a los vaivenes de la República chilena naciente. Esa "inmadurez" desembocaría en el golpe de Estado y la reducción drástica del pluralismo.

\section{Otra historia: el periodismo entre 1970 y 1973}

Si esos análisis parecen adecuados para describir las páginas editoriales de los diarios durante la UP, omiten un detalle significante: a diferencia del periodismo doctrinario, hecho

\footnotetext{
${ }^{8}$ Claudio Durán, El Mercurio: ideología y propaganda 1954-1994. Ensayos de interpretación bilógica y psico-histórica. Ensayo 1: propaganda de agitación en el periodo agosto 1972 - marzo 1973, Santiago de Chile, Ediciones Chileamérica-CESOC, 1995; Armand Mattelart, Michèle Mattelart, Mabel Piccini, "Los medios de comunicación de masa. La ideología de la prensa liberal en Chile", Cuadernos de la realidad nacional, $\mathrm{n}^{\circ}$ 3, marzo de 1970, PUC.

${ }^{9}$ Como lo enfatiza el historiador francés Philippe Gottraux: "no es porque la historia zanjó de hecho entre varios posibles [...], que eran ineluctablemente inscritos al inicio de la estructura objetiva de las posiciones, o en la conciencia y la voluntad". Ver: Philippe Gottraux, "Socialisme ou Barbarie, Un itinéraire saisi par l'histoire et la sociologie", en Yves Déloye, Bernard Voutat, Faire de la science politique, Paris: Belin, 2002, p. 191 (todas las traducciones del francés al español son personales).

${ }^{10}$ Robert Chaouad, "La résonance des temps", Revue internationale et stratégique, vol. 3, n 91, 2013, p. 68.

${ }^{11}$ Santa Cruz, op. cit., 1988.

${ }^{12}$ Según la lectura sistémico-institucionalista. Ver, entre otros, Arturo Valenzuela, The Origins of Democracy: Theorical Reflections on the Chilean Case, Cambridge, Cambridge University Press, 1983; Arturo Valenzuela, El quiebre de la democracia en Chile, Santiago de Chile, FLACSO, 1989; Claudio Veliz, "Continuidades y Rupturas en la Historia Chilena: Otra Hipótesis sobre la Crisis Chilena de 1973", Estudios Públicos, $\mathrm{n}^{\circ} 12,1983$, pp. 41-64.
} 
por equipos reducidos en torno a una figura editorial responsable jurídicamente ${ }^{13}$, los diarios en circulación entre 1970 y 1973 eran producidos por empresas que se estructuraban a partir de múltiples servicios específicos, salas de redacciones que agrupaban numerosos periodistas y una organización jerarquizada caracterizada por su complejidad. Antecedentes de este proceso se ven reflejados en los viajes que hizo Agustín Edwards McClure a Nueva York entre 1901 y 1904, para estudiar el funcionamiento interno y la organización de los servicios de recursos humanos de los diarios estadounidenses (principalmente el New York Herald) e importar las lógicas y técnicas en su propia empresa periodística, El Mercurio ${ }^{14}$. Entre las dos épocas, se racionalizó la producción de la prensa.

El contra-argumento se hace más fuerte cuando uno toma en cuenta el proceso de mercantilización del sistema mediático ${ }^{15}$. A nivel estructural, aparecieron y se consolidaron empresas mediáticas con estrategias de rentabilidad propias desde finales del XIX (con $E l$ Ferrocarril), y el mercado se iba segmentando, siguiendo sus propios ritmos y demandas. A nivel práctico, la mercantilización y la racionalización de los medios se conjugaron con la liberalización del periodismo a través de prácticas hoy consideradas clásicas: la separación entre opinión e información, la selección de los hechos y su producción bajo la forma de notas informativas, la impersonalidad del texto con el anonimato de los autores y la intrusión de los anuncios comerciales. En otras palabras, se asistió a "la constitución del diario o su estructura como sujeto de enunciación"16. Las novedades y el anuncio comercial ganan un espacio mayoritario como las "narrativas estandarizadas o géneros propiamente periodísticos"17. En torno a las audiencias, Eduardo Santa Cruz señala que, “(...) en un marco de relaciones y mediaciones complejas, comienza a configurarse, en sus características básicas, el público moderno de masas" ${ }^{\text {"18 }}$, ampliado y diversificado añadimos para sintetizar.

Parece entonces difícil asumir que entre 1970 y 1973 la posición política de los propietarios asegurara una línea política uniforme a la complejidad de los diarios. Lo que nos lleva a formular una hipótesis que parece hoy contra-intuitiva, porque matiza la contribución de la prensa en general, y de la prensa de izquierda en particular, al golpe de Estado. Durante la UP, la crisis política ${ }^{19}$ no llevaría a la ideologización uniforme de la

\footnotetext{
${ }^{13}$ Gonzalo Piwonka Figueroa, Orígenes de la libertad de prensa en Chile, Santiago de Chile, RIL Editores, 2000.

${ }^{14}$ Patricio Bernedo Pinto, Eduardo Arriagada Cardini, "Los Inicios de El Mercurio de Santiago en el Epistolario de Agustín Edwards Mac Clure (1899-1905)", Historia [online], vol. 35, 2002, pp. 13-33, <http://www.scielo.cl/scielo.php?script=sci_arttext\&pid=S0717-71942002003500003\&lng=es\&nrm=iso>; Carlos Silva Castro, Prensa y Periodismo en Chile (1812-1958), Santiago de Chile, Ediciones de la Universidad de Chile, 1958, p. 347.

${ }^{15}$ Carlos Ossandón B., Eduardo Santa Cruz A., Entre las alas y el plomo. La gestación de la prensa moderna en Chile, Santiago de Chile, Universidad ARCIS, LOM Ediciones, 1998.

${ }^{16}$ Eduardo Santa Cruz A., "Capítulo I: Conformación de espacios públicos, masificación y surgimiento de la prensa moderna" en Carlos Ossandón B., Eduardo Santa Cruz A. (1998), Ibid., p. 30.

${ }^{17}$ Ibid.

${ }^{18}$ Ibid., p. 26.

${ }^{19}$ Por "crisis política", designamos esos momentos extraordinarios en los que las relaciones políticas se polarizan, provocan movilizaciones multisectoriales y transformaciones abruptas de los espacios sociales.
} 
prensa. Proponemos entonces hacer una historia del periodismo de-sincronizada de la historia de los regímenes políticos. Implica buscar las discontinuidades propias del periodismo chileno, y no preconcebir el golpe de Estado como una ruptura evidente.

\section{Hacia una historia arqueológica del periodismo}

Para discutir esa hipótesis, buscamos la manera de identificar las huellas y las señales de los cambios históricos en el ejercicio del periodismo chileno. Primero, esa meta nos hizo tomar precauciones acerca de la manera de pensar esos cambios. Para no asumir que aparecieron necesariamente durante la crisis de 1970-1973, observamos un periodo más amplio que parte en 1953 y se termina con el golpe de Estado. Esto fue determinado a partir de un trabajo bibliográfico que puso en evidencia la profesionalización del periodismo chileno desde el giro del siglo XX. Ese movimiento se profundizó, a nivel práctico como legal, con una nueva generación del Círculo de periodistas ${ }^{20}$ que, a orillas de los años 1940, buscó el reconocimiento de las peculiaridades de un oficio ya pensado como profesión. Era el tiempo de la reivindicación de una formación universitaria, finalmente abierta en 1953 en la Universidad de Concepción y la Universidad de Chile, y extendida en 1956 a la PUC. El mismo año, se creó un Colegio de periodistas (Ley N¹2 045). A partir de esa ley, el Estado de compromiso chileno dejó una cierta autonomía a los periodistas para co-regular la profesión, es decir las entradas, a través de las formaciones universitarias y de las condiciones de empleabilidad (con la colegiación obligatoria y la instauración de la tarjeta de periodistas obligatoria como instrumento de reconocimiento y de protección, en 1968; y también la gestión paritaria de los organismos de protección social); y también las exclusiones (con un sistema de vigilancia de las prácticas a través de instancias de juicio y condena de los periodistas que tenían un comportamiento desviado). El campo periodístico se co-construye entre los periodistas y el Estado, cuyo mecanismo central de regulación de la población del campo fue la identidad profesional.

Tratamos entonces de ver si el periodismo ejercido entre 1970-1973 había mantenido los rasgos esenciales del periodismo profesional: la separación entre opinión e información, el anonimato de los periodistas y la selección de la información. Buscamos también signos sobre el posible surgimiento de otro tipo de registro periodístico que remitiera claramente al conflicto político (multiplicación de caricaturas, cambio de los

Dados los efectos de relato que están en juego en la calificación de ciertos periodos como "crisis" (que tienden a cosificar los elementos de la crisis y a naturalizar ciertos discursos a posteriori), decidimos de no recurrir a una definición más precisa. Al contrario, nuestro enfoque consiste en buscar "las estructuras comunes [que mantienen] un orden en lo que está presentado como caos". En esta perspectiva, ver: Robert Castel (1995), Les métamorphoses de la question sociale, Paris, Fayard; Michel Dobry, Sociologie des crises politiques, Paris, Presses de Sciences Po, 3e édition, 2009.

${ }_{20}$ Pensamos en: Juan Emilio Pacull (primer presidente del Colegio de periodistas de Chile), Ernesto Montenegro Nieto (primer director de la Escuela de periodismo de la Universidad de Chile), Santiago del Campo (que encabezó la Escuela después de Ernesto Montenegro), Ramón Cortéz Ponce (director de la Escuela hasta 1962 y autor del primer manual chileno de periodismo) o Mauricio Amster (figura central del grafismo y la tipografía desde su llegada desde España a Chile en 1939, y profesor de técnicas gráficas en la misma escuela). 
formatos, etc.). Y a pesar de que es necesario continuar la investigación para el periodo posterior a la UP para verificar si los cambios observados se mantienen o se modifican, la investigación realizada nos parece suficiente para discutir la ideologización de la prensa escrita durante la UP, y su contribución en la instalación de las condiciones que permitieron el golpe de Estado.

Para ser coherente con la crítica empírica que hicimos a partir de la observación de los títulos y de las líneas editoriales, como con la propuesta analítica de identificar los rasgos del profesionalismo periodístico durante la UP, tuvimos que indagar otro material. Decidimos primero observar tanto las páginas internas como las páginas de opinión de los diarios para comprender en qué medida se refería a la polarización ideológica de la sociedad chilena. Revisamos los textos periodísticos y, rápidamente, nos dimos cuenta de que esos textos debían ser analizados considerando las "materialidades" de la prensa escrita, es decir había que tomar en cuenta:

El conjunto de elementos que entran en juego para hacer existir físicamente el texto periódico: (...) los datos relativos al soporte (papel, libro, hoja, volumen, pantalla), así como las que más bien remiten a la página (tipografía, diagramación, secciones, inserción de anuncios [comerciales]). Hasta están incluidos en esta "materia" del diario factores más exteriores al texto periódico, cuando influyan directamente su fabricación y su difusión: precio de venta y condiciones de comercialización, plazos de transporte, relaciones entre periodistas e informantes. ${ }^{21}$

Dicho de otro modo, hicimos una "arqueología mediática" que nos permitió rastrear las técnicas y las tecnologías periodísticas usadas, sabiendo que "las culturas mediáticas son sedimentadas en diferentes capas, según los surcos del tiempo y de la materialidad"22.

Encontramos en ese enfoque la solución metodológica para reconstruir las rutinas periodísticas y la cultura profesional propias de los tres años que nos interesan, en relación directa con la crisis política. De esa manera, los archivos de prensa se tratan como fuente de otro proceso, que no tiene, necesariamente, relación con la ideologización de los contenidos debida a la polarización de la sociedad. Estos revelan la continuidad histórica de técnicas y prácticas que intentan ejercer un periodismo liberal de manera profesional. Así, concordamos con Eliseo Verón ${ }^{23}$ cuando afirma que es posible rastrear en los periódicos las huellas de su proceso de producción, es decir las marcas de un "discurso en acto" 24 .

\footnotetext{
${ }^{21}$ Alexis Lévrier, Alice Wrona (dir.), Matière et esprit du journal. Du Mercure Galant à Twitter, Paris : PUPS, collection « Histoire de l'imprimé », 2013, p. 8.

${ }^{22}$ Jussi Parikka, What Is Media Archaeology?, Cambridge, Polity Press, 2012, p. 2-3.

${ }^{23}$ Eliseo Verón, La semiosis social. Fragmentos de una teoría de la discursividad, Barcelona, Gedisa, 1988.

${ }^{24}$ Hans Stange, Claudio Salinas, "Rutinas periodísticas. Discusión y trayectos teóricos sobre el concepto y su estudio en la prensa chilena", Cuadernos de trabajo del ICEI, Santiago de Chile, Universidad de Chile, CECOM, 2009.
}

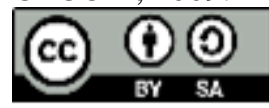


En esa perspectiva, se trabajaron los aspectos prácticos (reuniones de pauta, diagramación, relaciones con las fuentes, etc.), los aspectos discursivos (normas éticas, regulación del campo, formación al quehacer, etc.) y los aspectos estructurales (mercado mediático, recursos tecnológicos, transporte, etc.) del periodismo durante el periodo en cuestión. En términos prácticos, estudiamos cuatro diarios de circulación nacional: El Siglo, Clarín, La Tercera y El Mercurio. La elección de esos periódicos fue guiada por tres criterios: a) la política de las líneas editoriales de la época (de derecha con El Mercurio y La Tercera y de izquierda con El Siglo, medio impreso del Partido Comunista chileno, y Clarín, desde que está en manos de Víctor Pey en 1972); b) la tipología clásica que opone tabloides (Clarín y La Tercera) y prensa seria (El Siglo y El Mercurio) ${ }^{25}$; c) la continuidad en la circulación de esos diarios (todos participan en el mercado de la prensa desde 1954), estabilidad que permite recabar datos de segunda mano ${ }^{26}$. A continuación, realizamos un estudio formal de esos productos mediáticos (frecuencia de publicación, paginación, número de notas publicadas, fuentes convocadas...). Por último, para entender la evolución del tratamiento del espacio en los diarios chilenos entre 1970 y 1973, se compararon los cambios y continuidades de las pautas, de la diagramación y de los bloques-artículos (es decir el artículo escrito con el título, el lead, la ilustración, la leyenda, etc.).

En términos discursivos, el análisis articula la cultura periodística observada a partir de los archivos con los testimonios de 30 periodistas aproximadamente acerca de su cotidianidad laboral entre 1970 y 1973, obtenidos por medio de entrevistas que remiten a una historia oral $^{27}$. El objetivo de esa segunda etapa de la investigación era rastrear la memoria de los practicantes sobre la organización del proceso de fabricación de los diarios, y confrontar las regularidades e irregularidades establecidas a través de la observación de los archivos. Finalmente, y de manera transversal a las tres dimensiones investigadas, revisamos distintos tipos de archivos que permitieron completar la información. Por un lado, nos referimos a documentos de las escuelas de periodismo y del Colegio de periodistas para entender la acción normativa en el campo. Por otro lado, también recurrimos a leyes, cartas (entre otros, el documento que mandó la Sociedad Interamericana de Prensa a Allende en el caso del proyecto de nacionalización de La Papelera) o archivos de diarios de carácter popular, tales como Punto Final, Surazo, Mañanita, Nueva Habana, etc.

Mostraremos, en una primera etapa, que los elementos de continuidad en la práctica y la cultura del periodismo profesional revelan el interés de distinguir la historia del periodismo de la historia política. En una segunda etapa, proponemos trabajar sobre las temporalidades periodísticas para entender el cambio que ocurrió en la historia del periodismo chileno, durante la UP.

\footnotetext{
${ }^{25}$ Dooner, op. cit.; Sunkel, op. cit.

${ }^{26}$ Clarín es el último diario creado de la muestra (1954). Los otros ya circulaban (El Mercurio desde 1901; El Siglo desde 1940, clandestinamente durante el gobierno de Gabriel González Videl, a; La Tercera reemplaza a La Hora en 1949).

${ }^{27}$ Las transcripciones integrales de estas entrevistas están compiladas en el tomo 2 de nuestra tesis de doctorado. Cada vez que convocamos un extracto de esas entrevistas, hacemos referencia a este trabajo publicado en línea. Ver Faure, op. cit., 2014, Tomo 2.
} 


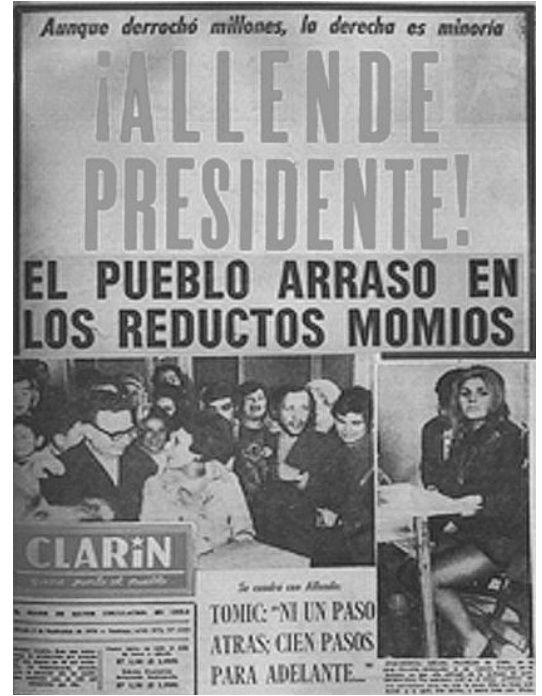

\section{Rutinas periodísticas y crisis política}

El primer resultado contradice directamente el diagnostico de analistas que sólo observan la ideologización de la prensa escrita entre 1970-1973. Sostenemos que esas miradas no consideran suficientemente la institucionalización del campo mediático, y su capacidad de resistencia a la fuerza centrífuga de la tormenta política.

Imagen n ${ }^{\circ}$ : El Clarín, 5 de septiembre de 1970

\section{Una ideologización profundamente contenida}

Durante la UP la lectura de los diarios estuvo ciertamente condicionada por la portada ${ }^{28}$, e intuimos que la última página también forma parte de los primeros lugares que consulta el lector. Del mismo modo, las páginas siguientes incluyen generalmente las columnas de opinión y las secciones editoriales (caricaturas, textos paródicos, etc.). La línea editorial de la prensa aparece entonces al principio (imágenes 1 y 2) y en sus últimas páginas, cuando son de reportaje (hasta 4 páginas el domingo, en El Siglo y El Mercurio). Sin embargo, una vez que se revisan las páginas interiores, se leen notas que remiten más bien a un periodismo informativo o interpretativo.

Sin embargo, para tener una visión compleja de los diarios, hace falta observar sus pautas $^{29}$ además de los títulos y de las portadas. La organización temática de los diarios mantiene continuidad, hasta en los cambios de pauta producto de la realización de eventos rituales y rutinarios (Te Deum o 21 de mayo). Desde un punto de vista sintético y esquemático, se puede señalar que las secuencias temáticas de los periódicos estudiados siguen este orden: Opinión, Política y Sociedad, Policiales, Internacional, Cultura y Espectáculo, Deportes. La variación del espacio de esas secciones muestra sin embargo las distintas prioridades de cada línea editorial, lo que contribuye, ciertamente, a la enunciación de preocupaciones políticas. Por ejemplo, se hace visible una preocupación por el sindicalismo en El Siglo, mientras en El Mercurio hay más lugar para la economía; la prensa tabloide, por su parte, dedicará más espacio a la sección policial y a la de deportes. No obstante, la separación espacial entre opinión e información no se desestructura como

\footnotetext{
${ }^{28}$ Particularmente porque una de las prácticas de consumo de los diarios consiste en consultar los títulos exhibidos alrededor de los kioscos, en cada esquina de las calles chilenas.

29 "La maqueta anticipando sobre el contenido (naturaleza y tamaño de los artículos y publicidades de las páginas, de las secciones de la edición del diario en preparación)" en Erik Neveu, "Glossaire", Sociologie du journalisme, Paris, Editions La Découverte, Coll. "Repères”, 2001, pp. 7-8 (traducción propia).
} 


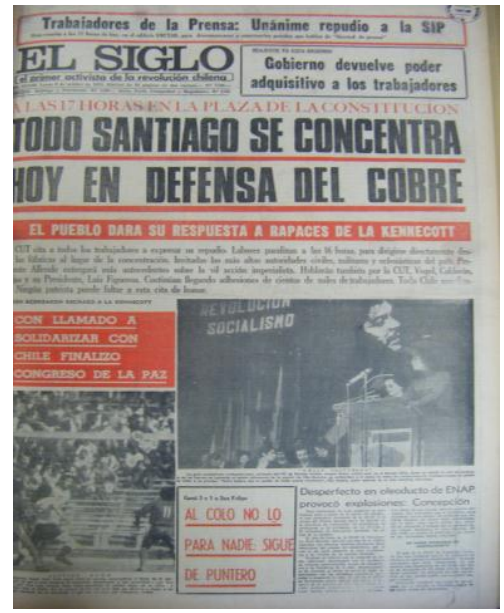

tampoco se esparce la línea editorial en otras de las páginas de los diarios no convencionalmente asignadas para esos contenidos. Como ya lo hemos escrito en otra parte: "Pese a la radical politización, se reconoce empíricamente la dicotomía liberal clásica entre opinión e información"30.

\section{Imagen n²: El Siglo, 09 de octubre de 1972}

En términos prácticos, en esa dicotomía opera una solidaridad corporativa que va más allá de la polarización ideológica. Un periodista del Siglo, que trabajaba en el palacio presidencial de La Moneda, recuerda lo que le parece paradójico hoy día: “(...) incluso a veces yo me quedaba hasta más tarde, y había una noticia: que el Ministro dijo no sé qué. Entonces yo llamaba al tipo del Mercurio, por teléfono desde el diario, y le decía: 'Mira, ocurrió esto'. Porque yo... si [él] no lo tenía, al otro día lo iban a amonestar, por lo menos, entonces ése era el espíritu que había en el gremio en esa época, de camaradería de trabajo, eso cambió brutalmente con el Golpe" 31 . Por su parte, un periodista de Clarín coincide con esta idea al señalar que el criterio de credibilidad profesional estaba encima de la batalla ideológica: "Es decir que había credibilidad en el otro periodista, en donde se confía en él"32. Esas palabras muestran que los valores que primaban se vinculaban estrechamente con la institucionalización del oficio periodístico.

Esa institucionalización se consolidó en parte gracias a las escuelas de periodismo, como ya lo explicamos. De este modo, para comprender cuáles eran los valores centrales del periodismo de la época, fue necesario mirar la enseñanza de la profesión en aquel entonces. En otras palabras, ¿tuvo el proyecto de la "vía chilena al socialismo" (según la expresión consagrada) una influencia sobre la manera de concebir y transmitir las prácticas y los valores periodísticos? Para contestar esa pregunta, analizamos las distintas mallas curriculares de las tres escuelas de periodismo. Estas muestran un enfoque cada vez más orientado hacia la técnica y la buena práctica, a pesar de su carácter generalista. En todos los programas se encuentran, por ejemplo, clases de periodismo informativo, de redacción y de tipografía ${ }^{33}$. Si los dos primeros años de las mallas curriculares (que duraban cuatro años) se dedican a dar una buena cultura general a los estudiantes, los años siguientes se

\footnotetext{
${ }^{30}$ Antoine Faure, "La crisis mediática durante la Unidad popular (1970-1973): ¿hacia una historia discontinua del periodismo chileno?", Actas del III Congreso INCOM, Concepción, 3 y 4 de noviembre 2016, 2016b, p. 42 .

${ }^{31}$ Entrevista a un periodista del Siglo. Faure, op. cit., 2014, Tomo 2, p. 200.

32 Ibid., Tomo 2, p.346.

${ }^{33}$ Un periodista que empezó sus estudios de periodismo antes del golpe de Estado recuerda con mucha malicia la enseñanza de la tipografía: "Hoy día es absolutamente ridículo, pero en esa época era saber que existía la Bold, la Time, la no sé cuánto, que las flechitas que indican que cambias de páginas se llaman teclas, eso no se me ha olvidado, pero de las otras no me acuerdo, los interlineados, una lata que no te explico (risas) "'. Ver: Faure, Ibid., Tomo 2, p. 247.
} 
centran en cursos enfocados en cuestiones técnicas (expresión, técnicas gráficas, fotografía, periodismo audiovisual, etc.), temáticas (periodismo cultural, económico, etc.) y otras relativas a la preparación en la cultura periodística (legislación y ética periodística, entre otros $)^{34}$.

Los testimonios recolectados revelan la importancia del periodismo informativo en la época, y también la relevancia de una formación orientada hacia el establecimiento de redes, por ejemplo, a través de la práctica profesional que realizaban al finalizar sus estudios. La formación se articula con la socialización para transmitir el quehacer periodístico. Un periodista que estudió en la Universidad de Chile explica: "Todas esas técnicas del periodismo informativo (...): el sagrado cliché de la pirámide invertida, los atributos de la noticia que son como 7 , que ya ni los recuerdo (...). Y, sobre todo, bueno, lo fundamental, los elementos de la noticia, o sea las preguntas que había que responder al contar la noticia. Eso para mí fue lo relevante, o sea explicar el qué, el por qué, el para qué, el dónde, el cuándo, el cómo, y organizar eso de acuerdo a su importancia. Porque en alguna noticia lo más importante podía ser el cómo, en el caso por ejemplo del tipo que murió por una papa en la boca, pero la muerte en sí no era tan relevante" 35 . Aquí se ve claramente que la tarea central enseñada al periodista consistía en ordenar cada noticia ${ }^{36}$. Un periodista que era estudiante a principios de 1973 detalla las clases prácticas que tuvo en la PUC: "Teníamos por cierto Redacción, varios cursos de redacción, Redacción 1, 2, 3. Teníamos, a ver, voy a ir por los ramos más técnicos-periodísticos. Redacción 1, 2, 3; Reportaje, por lo menos; Entrevista... Cada uno como cátedra distinta". Y recuerda con más precisión la clase de "Técnicas y Géneros Periodísticos": "Después teníamos, Técnica y Género Periodísticos, que era una especie de distinción de Periodismo informativo, Periodismo interpretativo, etcétera"37. El enfoque técnico-practico de esas clases es decisivo, y la legitimidad de los profesores para enseñar esos ramos radicaba en su

\footnotetext{
${ }^{34}$ Es también necesario tomar en cuenta el impacto de la Reforma Universitaria sobre los programas de las Escuelas de Periodismo. En una entrevista, una periodista asegura que no tocó la enseñanza práctica: "En los cursos de formación general, de Historia, de Ciencia Política, de Filosofía, entraba la coyuntura, entraba el contexto. En los cursos de técnica y eso, yo no recuerdo que hayamos cuestionado mucho". Sin embargo, otros periodistas atestiguan que ese evento, y específicamente el afiche "El Mercurio miente" colgado en el frontón de la casa central de la Pontificia Universidad Católica, incentivó su deseo de ser periodistas. También una periodista explica que el contexto de ebullición social propia de la Reforma Universitaria la empujó a trabajar como periodista sin terminar sus estudios, específicamente en Chile Hoy. En concordancia con nuestra hipótesis, esos ejemplos muestran que hay una índole política en la decisión de seguir una carrera periodística en la época, pero no se debe leer todo desde ese filtro. Ver: Faure, Ibid., Tomo 2.

${ }^{35}$ Ibid., p. 214.

${ }^{36}$ Para reforzar esta idea, es interesante la autobiografía del primer egresado de la Escuela de Periodismo de la Unviersidad de Chile. Recuerda la primera clase en la Universidad de Chile, dictada por Ramón Cortéz Ponce sobre las prácticas de reportaje. Ver: Alejandro Cabrera Ferrada, Los vencedores del sol: reportaje a creadores de y protagonistas de los primeros dieciséis años de vida de la primera Escuela Universitaria de Periodismo de Chile 1953-1968, Madrid, Pays Ltda, 1994.

${ }^{37}$ Ibid., p. 246.
} 
experiencia en la profesión, es decir su carácter de pares en el campo periodístico ${ }^{38}$.

Por último, ese aprendizaje se ratifica al final de sus estudios a través de la realización de una práctica profesional. Ese ejercicio pedagógico fue introducido por la Universidad de Chile con el decreto universitario $N^{\circ} 1823$ aprobado el 14 de junio de 1954 que indica lo siguiente: "En el curso del último año, los alumnos entrarán a practicar en algún diario, revista o agencia informativa". Esa experiencia permite confrontar los conocimientos adquiridos durante los años de estudio con el trabajo en terreno, ofrece la posibilidad a los estudiantes de entrar en contacto con el tipo de medio de comunicación en el que quieren trabajar, y funciona como un proceso de socialización en el que se validan las buenas prácticas y se corrigen las inadecuadas ${ }^{39}$. Sabiendo que las conexiones entre los estudiantes y las salas de redacción se hacen a través de sus futuros pares que enseñan en las escuelas. En síntesis, articular una arqueología de los medios y una historia oral del periodismo permite poner en evidencia que, frente a la crisis política durante la UP, las rutinas periodísticas profesionales estaban lo suficientemente asentadas para resistir a la polarización ideológica.

\section{La centralidad de la selección y jerarquización de las noticias}

Al ampliar la mirada hacia el periodo 1953 y 1973, constatamos que la profesión periodística alcanzó a asentar prácticas institucionalizadas antes de la Unidad Popular. Esas rutinas buscaban controlar el flujo de eventos cotidianos, lo que permitía ganar eficiencia en la producción de las noticias y del producto mediático, y dar legitimidad a los periodistas y las empresas mediáticas para regular los problemas discutidos en el espacio mediático. En otras palabras, lo que observamos a través de las continuidades son las resistencias de las rutinas periodísticas a la crisis política, lo que matiza la tesis de la ideologización transversal del campo periodístico.

En efecto, la profesión se había construido a través de un discurso de responsabilidad social que operaba por medio de la co-regulación del campo periodístico de parte del gremio y del Estado de compromiso. Esa responsabilidad se articulaba con la tarea mediática de selección y jerarquización de las noticias. Buena evidencia de ese dispositivo práctico-normativo son las deadlines, es decir los plazos de las distintas etapas de fabricación del diario que estructuraban este proceso y que seguían las mismas lógicas rutinarias. En los testimonios que recogimos, los periodistas describen las mismas etapas cotidianas: "reunión de pauta, contactos con la fuente (si es posible), reportaje y relaciones con las fuentes, escritura, negociaciones del espacio de publicación (tamaño del artículo y

\footnotetext{
${ }^{38}$ Esa práctica pedagógica está oficialmente reconocida: “La Dirección de la Escuela de Periodismo podrá proponer a la Facultad la elección de Miembros Académicos de aquellos periodistas que hayan desarrollado actividades sobresalientes en la profesión, de conformidad a lo establecido en el Art. $15^{\circ}$ del Estatuto Orgánico de la Enseñanza Universitaria [Mayúsculas en el texto]”, artículo 6, decreto universitario $\mathrm{n}^{\circ} 1823$, Universidad de Chile, 14 de junio de 1954.

${ }^{39}$ Warren Breed, "Social control in the Newsroom: A Funcional Analysis", Social Forces, Vol. 33, n4, 1955, pp.326-355.
} 
posibles ilustraciones), lugar de publicación en la pauta y título" ${ }^{\text {, }}$. Un periodista de Clarín comenta su llegada en la redacción de la siguiente manera: "Empiezas a aprender la cotidianeidad del diario. Todos los días, llega una noticia que el periodista tiene que seguir".

Ese dispositivo funciona justamente a partir de la tecnología de la pauta, es decir, la reunión de pauta y la cuadrícula espacial de los diarios. En el testimonio anterior se lee la función de la reunión de pauta que planifica y anticipa la cuadrícula de los diarios. Así, planteamos que opera una secuenciación rutinaria del proceso de fabricación de los diarios, que consiste en jerarquizar las noticias a través de la diagramación de los diarios y en jerarquizar los elementos de la noticia ordenados por la pirámide invertida. Son esos elementos que menciona decisivamente el periodista del Siglo en su testimonio sobre la centralidad de la importancia periodística, implementada por ejemplo por la organización de los "5 W” (¿Qué? ¿Quién? ¿Cuándo? ¿Dónde? ¿Por qué?). En otras palabras, el quehacer periodístico está centrado en la atribución de importancia a las noticias (la newsworthiness ${ }^{41}$ ) como regla de repartición espacial de las notas y regla de enunciación periodística. La meta apunta a canalizar el flujo de noticias ${ }^{42}$, lo que activa la figura clásica del gatekeeper (guardabarrera) ${ }^{43}$.

Por lo tanto, los elementos de continuidad que constatamos revelan las resistencias periodísticas al conflicto político. Se expresan a través de rutinas que buscan, especialmente, regular la temporalidad institucional de la profesión, orientada hacia el trabajo de agenda-setting ${ }^{44}$. En otras palabras, lo importante en la cotidianidad de los periodistas era definir de qué se habla en los diarios, a partir de tareas de selección y jerarquización de las noticias. Para expresarlo con los conceptos de Eduardo Santa Cruz, la "estrategia periodística"45 de los diarios en circulación durante la UP no se re-articula en torno a la línea editorial de los diarios, como lo plantea la tesis de la ideologización de los medios de comunicación. A pesar de la crisis política, el periodismo liberal se mantuvo vigente gracias a prácticas institucionalizadas que siguen tratando de manejar lo imprevisto. En ese sentido, la discontinuidad histórica del periodismo chileno no se encuentra durante la Unidad Popular, sino en la transformación del oficio de una profesión, a mitad del siglo XX. Para entender en qué consistió el periodismo durante la UP es necesario tomar en cuenta la variable temporal de la crisis.

\footnotetext{
${ }^{40}$ Faure, op. cit., 2016b, p. 47.

${ }^{41}$ Herbert Gans, Deciding What's News: A Study of CBS Evening News, NBC Nightly News, Newsweek and Time, New York, Pantheon Books/London, Constable, 1980.

${ }^{42}$ Es decir, el volumen de las noticias en el espacio mediático nacional, y su distribución en el tiempo y el espacio. Para una aproximación, ver: Soulages, J. C., Les mises en scènes visuelles de l'information. Etude comparée France, Espagne, Etats-Unis, Paris, Nathan, 1999.

${ }^{43}$ Para más detalle sobre el trabajo de filtro que hacen los periodistas, ver: Manuel López, Cómo se trabajan las noticias, Barcelona, Paidós, 1995; Maxwell Mac Combs, Setting the Agenda: The Mass Media and Public Opinion, Cambridge, Polity Press, 2004.

${ }^{44}$ Maxwell Mac Combs M., Donald Shaw, "The agenda setting function of the mass media", Public Opinion Quarterly, vol. 36, 1972, p. 176-187.

45 "Un conjunto de objetivos y definiciones políticas, periodísticas y empresariales que, combinadas entre sí, le dan un perfil al medio" en Ossandón B., Santa Cruz A., op. cit., p. 44.
} 


\section{¿La emergencia de una nueva temporalidad periodística?}

Rastrear la manera con la que se hacía periodismo durante la UP muestra que la hipótesis de la contribución de la prensa escrita a instalar las condiciones que propiciaron el golpe de Estado es difícil de defender, por lo menos a partir del argumento sobre la ideologización de los medios. En cambio, si observamos las rutinas periodísticas y analizamos el discurso normativo sobre el periodismo, es posible abrir otra hipótesis. En este sentido, durante la UP se vislumbran los gérmenes de una transformación en la temporalidad profesional, es decir, se aprecia "un régimen de temporalidad periodística que mantuvo el manejo del flujo de noticias a pesar de los eventos, la urgencia social o la irrupción de lo imprevisible"46. En otras palabras, la crisis política no provocó una ideologización del discurso periodístico, sino que ejerció una presión temporal sobre las rutinas y gatilla otra prioridad en el quehacer cotidiano. La urgencia mediática desconfiguró las rutinas y las normas periodísticas, mientras que la función de selección estuvo distorsionada por la necesidad de mediatizar una cantidad voluminosa y acelerada de noticias. Una vez constatada la presión de la crisis política a partir del volumen y del ritmo de los eventos, nos enfocaremos entonces sobre el desarreglo que provocó en el quehacer periodístico, tanto a nivel práctico como normativo.

\section{La presión temporal de la crisis política}

El flujo de hechos y acontecimientos se dilató durante la UP, sin duda, a causa de la tensión propia a la crisis política. Sin entrar en un conteo imposible de cerrar, podemos recordar la cantidad impresionante de documentales, películas, libros o novelas gráficas que se relacionaron con en el trabajo de memoria de los tres años de gobierno de Allende. Cada uno evoca nuevas fechas, otros puntos de vista en el seno mismo de la crisis o propone otras lecturas de acontecimientos que ya están saturados de sentido. En términos académicos, las cronologías registran la multiplicación de los eventos en una lista cada año más larga ${ }^{47}$. El relato histórico recuerda la frecuencia de las decisiones; la cadencia "de los cambios de gobierno; la rítmica del conflicto social" 48 . Esto lo pone en evidencia un ejemplo simbólico: la cantidad anual de huelgas pasó de 977 en 1969 a 3652 en $1973^{49}$.

En ese contexto, la prensa y los medios de comunicación tuvieron un cierto éxito. Las audiencias fueron las más altas de la historia: con 7.884.768 habitantes, se compraron casi 850.000 diarios cada día ${ }^{50}$. El mercado mediático contó con numerosas publicaciones y

\footnotetext{
${ }^{46}$ Inferimos aquí a partir del texto: Philip Schlesinger, "Newsmen and the Time-Machine", British Journal of Sociology, vol. 28, n³, 1977, pp.336-350.

${ }^{47}$ Entre otros, ver: Franck Gaudichaud, Chili 1970-1973. Mille jours qui ébranlèrent le monde, Rennes : PUR, «Amériques », 2013; Ingrid Seguel Boccara, Les passions politiques au Chili durant l'Unité populaire (19701973): un essai d'analyse systémique, Paris: L'Harmattan, 1997.

${ }^{48}$ Faure, op. cit., 2016b, pp. 48-49.

${ }^{49}$ Ruy Mauro Marini, El Reforma y la Revolución. Estudios sobre Chile, México D.F., ERA, 1976, p. 152.

${ }^{50}$ Santa Cruz, op. cit., 1988.
} 
medios de comunicación que siguen creándose, por ejemplo, con los semanales de la Editorial Quimantú ${ }^{51}$. En sus páginas, los diarios difundieron cada día noticias en un volumen considerado como el más elevado de la historia de la prensa chilena. Como ejemplo, podemos señalar un promedio de 106 notas por diario en $1971^{52}$. Ese volumen aumentó hasta que en 1973 se alcanzaron las 132 noticias publicadas en promedio diariamente.

En términos tecnológicos, los medios de difusión no cambiaron, pero hay una "innovación” que potencia esa presión de los eventos, con la importación en 1971 de la primera rotativa offset del país en La Sociedad Imprenta Horizonte, del Partido Comunista Chileno $^{53}$. Esa tecnología re-estructuró las etapas del ciclo de producción, permitió un aumento de la paginación (que no ocurrirá) como una estandarización de las pautas, y favoreció el uso de ilustraciones visuales ${ }^{54}$. Con esa tecnología, se abrieron posibilidades temporales en el ciclo de producción de los diarios, y nuevas posibilidades de gestión de su espacio, considerando además que Horizonte fue la sociedad impresora de varias publicaciones entre 1970 y 1973 (El Siglo, Las Noticias de Última Hora, Puro Chile, Quinta Rueda, etc. $)^{55}$.

Entre esas nuevas posibilidades tecnológicas y la crisis política, se aceleró el tiempo mediático. La multiplicación de las publicaciones, específicamente de los vespertinos, ofreció a los periodistas la posibilidad de tomar en cuenta lo que escribieron sus pares, y los lectores tuvieron más posibilidades de informarse, al ritmo de dos veces al día. Las cifras de escucha de radio muestran también que el consumo de información fue alto, y que la presión de la crisis aumentó el volumen y el ritmo del flujo de noticias. Por su parte, la televisión también contribuyó a esa abundancia, a través del aumento continuo de los espectadores y de la programación diaria: ;en 1963 se registraron 35.000 televisores en el territorio chileno y en 1967 son más de 55.000, llegando a los 300.000 en $1970 !^{56}$ El tiempo de transmisión también se extendió hasta unas 10 horas diarias en 1973.

La presión de los eventos catalizó entonces el flujo de noticias. Otra discontinuidad apareció entonces durante la Unidad Popular: no se trataría de una ideologización del campo, sino de la distorsión del quehacer periodístico debido a la presión temporal de la crisis política. Para discutir esta nueva hipótesis, queremos ver cómo se comportaron los

${ }^{51}$ Editorial estatal nacida de la nacionalización de Zig-Zag en 1971, por parte del gobierno de la Unidad Popular. Basada en una gestión colegial y representativa de las fuerzas políticas de la coalición, Quimantú propone numerosas publicaciones, del comic hasta el libro (con varias colecciones), pasando por revistas (Ahora, Mayoría, por ejemplo), magazines o cuadernos de educación popular.

52119 en El Mercurio, 108.5 en Clarín, 93.3 en El Siglo y 127 en La Tercera.

${ }^{53}$ Gracias al don de Neruda después de ganarse el premio Lenin por la paz y el premio Nobel de literatura (1971).

${ }^{54}$ Nicolas Kaciaf, Les pages «politique ». Histoire du journalisme politique dans la presse française (19452006), Paris, PUR, coll. "Res Publica", 2013, p. 88.

${ }^{55}$ Aquí se ve la potencia editorial del Partido Comunista en aquel entonces, entre su diario serio (El Siglo), un tabloide político (Puro Chile), su revista mensual sobre cultura (Quinta Rueda), el diario del Partido Socialista (Las Noticias de Última Hora), sin contar con el trabajo de producción de panfletos, afiches o letreros destinados al trabajo político; como folletines y otros documentos internos, etc.

${ }^{56}$ Mattelart, Mattelart, Piccini, op. cit., p. 72. 
periodistas en esta configuración y cómo usaron las normas y prácticas profesionales rutinarias.

\section{La prioridad práctica del flujo de noticias}

La arqueología de los medios se revela de nuevo decisiva para evaluar cómo, en términos prácticos, los criterios que administran la importancia periodística se adaptan (o no) al flujo dilatado de noticias. Concretamente, el dispositivo de deadlines, cuya importancia en el quehacer periodístico subrayamos anteriormente, se desarregla. Vemos, a través de desajustes materiales, que en el cotidiano periodístico, se priorizó cada día más el volumen y el ritmo del flujo de noticias sobre la función de selección de los hechos (la función de filtro).

El contexto de fuerte competencia comercial y política, como de intensidad noticiosa, aceleró la reactividad periodística multiplicando las posibilidades de tomar en cuenta sus pares ${ }^{57}$, como bien lo testifica esta declaración de un periodista de la época: "Cada uno de nosotros tenía los diarios, la radio y la televisión. (...) Cuando había algo, salíamos corriendo, uno detrás del otro. El que tenía la información era el mejor" ${ }^{58}$. En esa "carrera" por la noticia, las condiciones materiales de los diarios pudieron constituirse en un obstáculo. La paginación se mantuvo estable, oscilando entre 12 y 48 páginas según el diario, y no se constatan cambios entre 1970 y 1973. Las principales variaciones se identifican para el día domingo (en el que los diarios son tradicionalmente más voluminosos) o por la Navidad (los anuncios comerciales disputen el espacio de publicación de manera intensa). En consecuencia, las luchas por el espacio, que oponen publicistas y periodistas, fueron fuertes durante la UP. Un miembro del primer grupo afirma: “(...) Las empresas de publicidad decían 'queremos la página de la derecha, después la política o antes la política'. Y es aquí que teníamos muchos problemas con el director. (...) Pero vendíamos esa página, y había que defenderla para que se mantenga su número (...). Entonces tenía que quedarme hasta el cierre del diario para que no cambiaran la página de la derecha. Era una lucha constante" ${ }^{\$ 5}$. Vemos entonces que, a pesar de la presión de la crisis política, los criterios de la redacción no ganaron espacio, lo que no facilita la función de guardabarrera, que opera el filtro entre los hechos.

Esas dificultades se hacen visibles en la relativa desorganización espacial de los diarios, donde aparecieron ajustes y excepciones formales, como bien lo muestra la comparación entre dos páginas del Siglo, una de mayo de 1971 y la otra de octubre 1972 (imagen $\mathbf{n}^{\circ}$ 3). La cuadrícula de los diarios sigue existiendo (nunca desaparecerá) pero se desordena: ciertas columnas desbordan el bloque-artículo adyacente, y se publica mucho más noticias blandas, es decir noticias cortas y breves que no benefician de un trabajo de enfatización) con apenas una fuente usada (a partir de 1972, la cantidad de fuentes por nota

\footnotetext{
57 Según la lógica de “circulación circular” de la información, cf. Pierre Bourdieu, Sur la télévision, Paris, Raisons d'agir, 1996, p. 22.

${ }^{58}$ Entrevista con un periodista de Clarín. Ver: Faure, op. cit., 2014, Tomo 2, p. 347.

59 Ibid., p. 342.
}

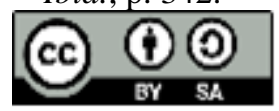


baja a 1,05 en promedio). Esos ajustes muestran los intentos para adaptarse a la urgencia mediática y la densidad del flujo de noticias a pesar de la estabilidad del espacio de publicación $^{60}$.

Imagen n³: Comparación visual de dos páginas de El Siglo

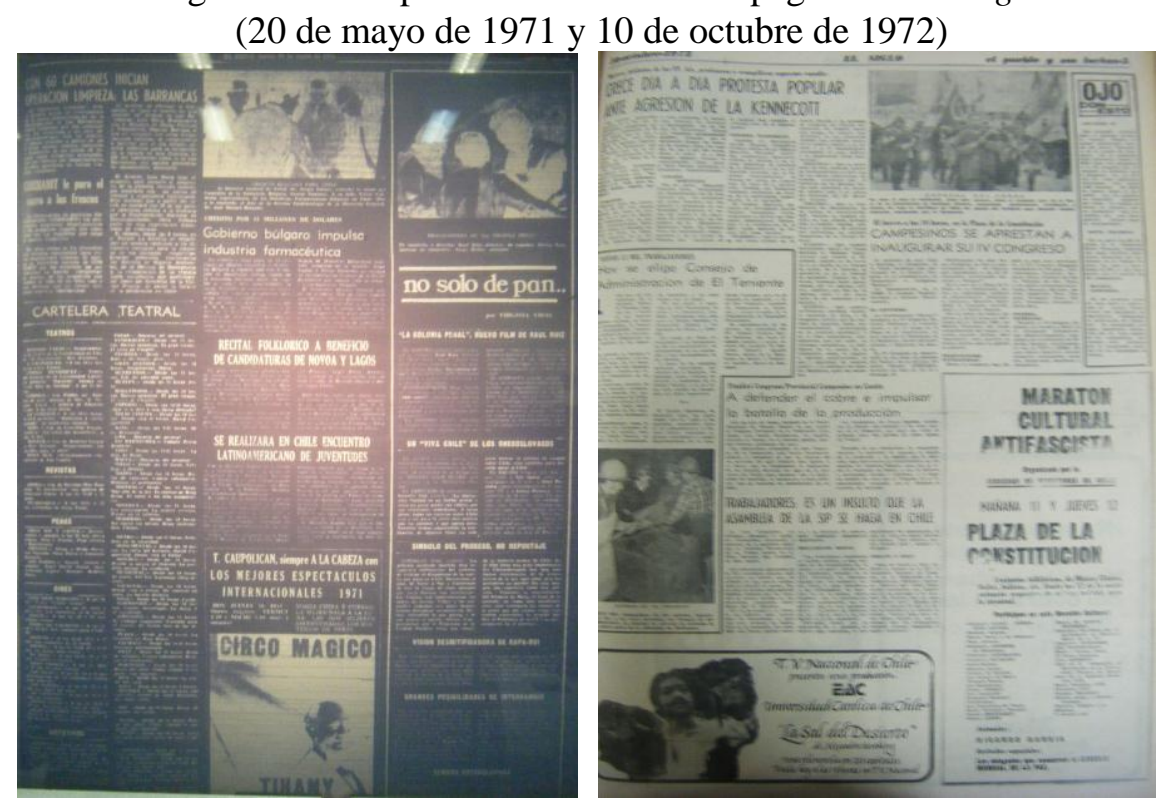

La crisis engendró nuevas precauciones periodísticas, de alcance temporal. Por ejemplo, se postergó el deadline de la sección política en Clarín: "todo lo que era de nivel internacional, economía, sindical cerraba primero, y se guardaba siempre la política y la portada para el último momento" 61 . Entonces, todos los elementos prácticos dejan ver una desorganización material que remite a otra discontinuidad en la historia del periodismo chileno: una nueva temporalidad profesional. Esa lógica práctica se encarna también en las críticas normativas que aparecen a lo largo del periodo.

\section{Las críticas normativas}

Frente a la presión de los eventos, y a las dificultades cotidianas, se encuentran prácticas que rompieron con el periodismo liberal en diarios relacionados a los dos campos políticos. Los dos hitos periodísticos que representan los cambios de diagramación de la portada del Mercurio, el 15 de junio (imagen $\mathbf{n}^{\circ}$ 4) y el 5 de septiembre 1973 (imagen $\mathbf{n}^{\circ} \mathbf{5}$ ), remiten

\footnotetext{
${ }^{60}$ En ese sentido, no es una casualidad que en el seno de la crisis, la pareja Mattelart planteara el problema de la táctica comunicacional en la urgencia revolucionaria. Ver: Armand Mattelart, Michèle Mattelart, "Ruptura y continuidad en la comunicación: puntos para una polémica", Cuadernos de Realidad Nacional (CEREN), $\mathrm{n}^{\circ} 12$, abril de 1972, pp. 100-144.

${ }^{61}$ Entrevista con un periodista de Clarín. Faure, op. cit., 2014, Tomo 2, p. 347.
} 


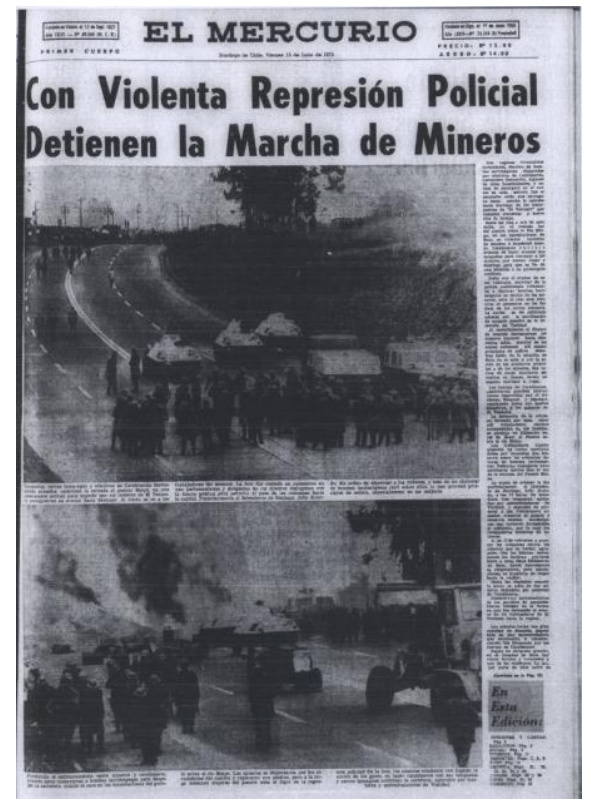

Imagen $n^{\circ} 4$ : Portada del Mercurio, el 15 de junio de 1973

Imagen n5: Portada del Mercurio, el 5 de septiembre de 1973

En todas esas publicaciones, las contra-conductas experimentaron con las formas visuales y los códigos del periodismo profesional, jugaron con el tamaño de los textos y siguieron una diagramación más creativa que no calza con la cuadrícula clásica. Entre la diversidad de voces incluidas y la creatividad formal, la mediación del gatekeeper quedó

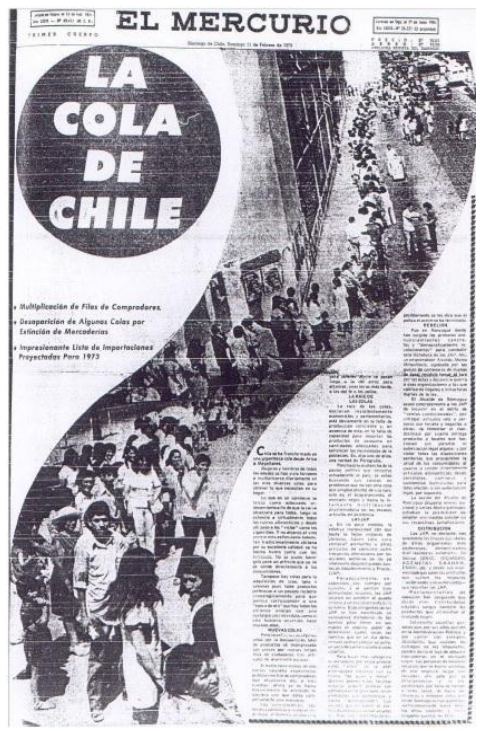
truncada. Esa función y sus valores clásicos fueron, por ejemplo, cuestionados durante la Asamblea de los periodistas de izquierda (abril 1971). Como su nombre lo indica, esa agrupación apuntaba a defender el periodismo comprometido. Durante esa Asamblea, 320 profesionales, políticos (incluido Salvador Allende) y académicos (Armand Mattelart por ejemplo ${ }^{65}$ ), discutieron sobre la autonomía y las fronteras de la profesión, como también de las buenas prácticas. Asimismo, en este contexto, denunciaron el velo de la objetividad. La Asamblea quiso instalar una competencia al monopolio de representación y regulación del Colegio de periodistas, a partir de una postura crítica. Es así que enjuiciaron desigualdades

\footnotetext{
${ }^{62}$ Tupper, op. cit., 2003.

${ }^{63}$ Santa Cruz, op. cit., 1988.

${ }^{64}$ Ibid.

${ }^{65}$ Cuyas críticas teóricas van en el sentido de las contestaciones gremiales. Ver Mattelart, Mattelart, Piccini, op. cit., 1970 ; Mattelart, op. cit., 1972 ; etc.
}

por un lado a tácticas propagandísticas ${ }^{62}$, pero rebaten, sobre todo, las normas de la profesión que El Mercurio alternativa como Surazo (Concepción) o Mañanita (Talca), es decir diarios que nacieron de las luchas lideradas por periodistas profesionales, ponen en tela de juicio el trabajo de selección de las noticias, al citar otras voces en los diarios o dejándoles espacios para vehicular sus opiniones. Esos diarios refuerzan una esfera pública plebeya ${ }^{64}$ que había aparecido en el cambio de siglo y que está alimentada, por ejemplo, por las publicaciones de los Cordones Industriales durante la UP (Nueva Habana, etc.).

.


de acceso a los medios; que Manuel Cabieses, el presidente de la Asamblea y director del semanal Punto Final, ligado al Movimiento de Izquierda Revolucionaria (MIR), incentivó el gesto de dar la palabra a otras voces; mientras que Salvador Allende llamó a construir una comunidad autónoma y homogénea redefiniendo las fronteras de la profesión ${ }^{66}$. Los argumentos apuntaron a criticar la concentración capitalista de las empresas periodísticas, a partir de una emancipación de los valores y las normas liberales del periodismo.

Para sintetizar, todas esas contra-prácticas y contra-conductas muestran que las temporalidades de las rutinas profesionales fueron superadas, interrogadas e invertidas. Los periodistas tuvieron que ajustar su quehacer cotidiano para captar la mayor parte de los eventos, lo que redujo la rigidez de la cuadrícula de los diarios, el trabajo de selección de las noticias y la figura discursiva del gatekeeper. Pero, para afirmar que la reactividad periodística cambia de sentido hay que indagar del otro lado del golpe de Estado, para saber si la lógica del flujo sigue prioritaria por encima del trabajo de selección de las noticias. En otras palabras, para observar si la lógica de circulación del flujo mediático ordena paulatinamente el quehacer periodístico.

\section{La consolidación de una nueva temporalidad, más allá de un pluralismo limitado}

Irrumpió el golpe de Estado. La sociedad chilena, que se pensaba anclada en una tradición democrática excepcional $^{67}$, entra en una etapa que pronto se confirmará como oscura, y característica de los regímenes autoritarios, es decir de pluralismo limitado ${ }^{68}$. Entre muchas otras cosas, significó la represión, el exilio y el cierre del espacio público. Y constituyó una ruptura innegable del porvenir histórico en todos los ámbitos sociales. Esa visión de la historia chilena reciente es cada día más cuestionada ${ }^{69}$, y nos parece que la historia del periodismo también muestra ciertas continuidades que asientan un poco más la hipótesis de

\footnotetext{
66 Para más detalle, ver: "La Asamblea de los periodistas de izquierda", Punto Final, "Documentos", Suplemento de edición, $n^{\circ} 129$, martes 27 de abril de 1971, <http://www.pfmemoriahistorica.org/PDFs/1971/PF_129_doc.pdf>

${ }^{67}$ Visión fuertemente criticada: Edward Blumenthal, Julio Pinto Vallejos, El mito de la excepcionalidad chilena: un proyecto de construcción identitaria, Santiago de Chile, PUC, 2004; Joaquín Fernández, Regionalismo, liberalismo y rebelión. Copiapó en la Guerra Civil de 1859, Santiago de Chile, RIL Editores, 2016; Alfredo Jocelyn-Holt, “¿Un proyecto nacional exitoso? La supuesta excepcionalidad chilena" in Francisco Colom González (ed.), Relatos de Nación. La construcción de las identidades nacionales en el mundo hispánico, Madrid, Iberoamericana/Vervuert, 2005.

${ }^{68}$ Juan Linz, "Una interpretación de los regímenes autoritario”, Revista de sociología, vol. 8, 1978, pp. 11-26.

${ }^{69}$ Manuel Gárate Chateau, La revolución capitalista de Chile (1973-2003), Editorial Universidad Alberto Hurtado, Santiago de Chile, 2012. El proyecto FONDECYT No 1150819, liderado por el Dr. Luis Ortega Martínez y titulado "El itinerario del proyecto monetarista chileno (1952-1975)" tiene una perspectiva similar. En una columna muy interesante, Fernando Muñoz plantea una continuidad en el proyecto político conservador, a través del ejemplo de las resistencias al proyecto de Escuela Nacional Unificada. Ver: Fernando Muñoz, "La actualidad de los conflictos político-jurídicos del pasado (II): la Escuela Nacional Unificada", RedSeca, Revista de Actualidad Política, Social y Cultural, Santiago de Chile, 5 de septiembre 2012. <http://www.redseca.cl/?p=3415> (consultado el 6 de septiembre de 2013).
} 
un cambio de la temporalidad profesional.

No desarrollaremos mayormente nuestro primer argumento, dado que lo hicimos en otra parte $\mathrm{p}^{70}$. Lo importante es notar que existe cierta continuidad práctica y cultural en el quehacer periodístico, más allá del golpe de Estado. Esa continuidad tiene en parte los rasgos del mito de la objetividad, por lo menos en la memoria que tienen los periodistas sobre su profesión. En pocas palabras, este mito se basa en el oficialismo de las fuentes, con la que los periodistas admiten tener cierto grado de familiaridad; en el uso del género informativo en $90 \%$ de las noticias; en la atribución jerárquica de las noticias; y en el empleo sistemático de la pirámide invertida.

Sin embargo, y son las pistas que nos hacen pensar que la temporalidad del flujo se consolida, el profesionalismo periodístico estaba cambiando de lógica: "el ritmo del flujo suplanta el tiempo de la agenda"71. La presión ya no se expresa bajo la urgencia de la crisis política, sino que el periodista profesional no estuvo autorizado a ejercer su función ya clásica de gatekeeper, en un "estado de urgencia". El control político, policial, económico y jurídico de los contenidos neutralizó el trabajo de selección de la información. Así, sólo circularon las voces autorizadas, fueran empresas mediáticas, fuentes periodísticas o autores de columnas ${ }^{72}$. Control, amenazas, represión y censura también construyeron un ambiente de autocensura de parte de los periodistas. Todas esas decisiones gubernamentales redujeron el flujo de noticias publicado cotidianamente. Así, a diferencia de lo mencionado en otro apartado para el periodo de la UP, en 1981 los diarios publicaron unas sesenta noticias cada día, en promedio ${ }^{73}$.

En ese sentido, las transformaciones de los formatos de los diarios influyeron tanto sobre la reducción de espacio de información ${ }^{74}$, como sobre el aumento de los espacios publicitarios $^{75}$, lo que redujo automáticamente la autonomía de los periodistas ${ }^{76}$. De hecho, en los testimonios posteriores de los profesionales, la temporalidad legitima los arreglos y los usos periodísticos, lo que muestra un movimiento de normalización de la prioridad del flujo de noticias. La función del gatekeeper ya ocupó un lugar en el proceso de fabricación

\footnotetext{
70 Todos los elementos que aparecen sintetizados en este párrafo están desarrollados en Antoine Faure, Claudio Salinas, Hans Stange, "The Dominance of Common Sense. The Influence of the Media System on Professional Practices of Journalists in Chile, 1970-2000” in Manuel Puppis, Matthias Künzler, Oliver Jarren (ed.), Media Structures and Media Performance: State of and Perspectives for Communication Research, Series “Relation”, Zurich: IPMZ, 2013, p.283-301.

${ }^{71}$ Faure, op. cit., 2016b, p. 51.

${ }^{72}$ La Junta Militar cierra una gran cantidad de medios de comunicación bajo criterios anti-marxistas (entre ellos, El Siglo, Las Noticias de Última Hora, Puro Chile). Ver: Guillermo Esteban Geoffroy, Guillermo Sunkel, Concentración Económica de los Medios de Comunicación, Santiago de Chile, LOM Ediciones, 2001.

${ }^{73}$ A la excepción de La Tercera que publica en promedio 114 noticias diarias.

${ }^{74}$ En oposición al espacio de opinión como a los avisos comerciales.

${ }^{75}$ Faure, Salinas, Stange, op. cit.

${ }^{76}$ En 1981 los diarios publicaban unas sesenta noticias en promedio, con excepción de La Tercera (114 noticias diarias en promedio). Se observa "una relación inversamente proporcional entre la aumentación de las páginas de los diarios y la diminución de las noticias publicadas" en Salinas, Stange, op. cit. 2009. El tamaño de los diarios y el crecimiento del espacio comercial son factores determinantes.
} 
de los diarios, a pesar de que los periodistas se esforzaron en mostrar la continuidad de su rol social. Varias prácticas de selección y jerarquización se seguían usando, pero ya no tienen la primacía en la organización del quehacer cotidiano. Así, la lógica práctica consistía en reducir las mediaciones para que el flujo de noticias sea fluido. Lo que, a la vez, legitimó de nuevo el rol social del periodista profesional y dio cierto realismo a su discurso.

En efecto, una vez comenzada la dictadura, la profesión había perdido su papel legitimador, dado que las instituciones del campo no podían ejercer el trabajo discursivo que permitía asentar las normas periodísticas. La escuela de periodismo de la Universidad de Chile fue cerrada, y las otras escuelas fueron intervenidas. De hecho, los representantes del Colegio de Periodistas eran nombrados, hasta obtener de nuevo el derecho de elección en 1981. En otras palabras, los profesionales perdieron en buena parte la gestión de las entradas y exclusiones del campo, así como la transmisión de las normas y buenas prácticas $^{77}$. La profesión quedó entonces desposeída del dispositivo central de su autonomía. Y si a partir de 1981 el Colegio enfrentó de nuevo la política de comunicación del régimen, la asociatividad ya no era obligatoria. El organismo no recuperó su lugar en la regulación del campo, se dedicó más bien a mantener una autonomía que ya sólo pasaba por la mera circulación de un flujo de noticias vaciado e intervenido. De hecho, el autoritarismo forzó la oposición mediático-política a luchar desde la misma lógica, la meta fue "publicar frecuentemente a pesar de las presiones y la represión"78.

Con el régimen autoritario, la lógica temporal de los periodistas profesionales chilenos parece re-articularse en torno a la circulación de un flujo de noticias optimizado según las condiciones de ejercicio de la profesión. La urgencia y el volumen de noticias enmarcaron el uso de las prácticas de selección y jerarquización. Habría que confirmar esa tendencia, específicamente en el caso del periodismo de televisión, que para esas fechas ocupaba el lugar central en el sistema mediático ${ }^{79}$ y que tenía la capacidad de emitir en vivo regularmente y masivamente ${ }^{80}$. Lo interesante, entonces, residiría en el nacimiento de la

${ }^{77}$ De manera general, varias prácticas políticas y reformas legales debilitaron los colegios profesionales y redujeron sus posibilidades de regulación ética como social. Pensamos en las expropiaciones de bienes a continuación del golpe de Estado y la designación de los dirigentes de los gremios, como en la Constitución de 1980 que les priva "de su carácter obligatorio, de casi todas sus funciones autorregulatorias y de casi todas sus prerrogativas" y el Decreto-Ley N³.621 (7 de febrero de 1981) que les transforma en asociaciones. Ver: Gabriel Guzmán Riquelme, "Colegios profesionales y asociaciones gremiales durante el proceso de recuperación de la democracia en Chile”, Informe de practica en el Museo de la Memoria y de los Derechos Humanos, 2012, p. 24.

${ }^{78}$ Faure, op. cit., 2016b, p. 52.

${ }^{79}$ Es suficiente mirar las teleseries históricas que tratan del periodo de la Dictadura para evaluar el alto peso memorial de la televisión y por ende su centralidad en el cotidiano de los años 1980. También son las bases sobre las que la política adoptó las formas y los formatos de la televisión (pensamos en la fuerza simbólica del "dedo de Lagos"). Para ver una aprehensión de los cambios que implica esa tendencia de mediatización de la política, ver: Juan Pablo Arancibia. Comunicación política. Fragmentos para una genealogía de la mediatización en Chile, Santiago de Chile, LOM, Universidad ARCIS, 2006.

${ }^{80}$ Ese dispositivo implica una forma de inmediatez en el tratamiento del evento. Tal como una forma pura de realismo periodístico, borra la mirada de la cámara sobre el evento, a pesar de todas las decisiones sobre el ángulo de grabación, el montaje en tiempo real, los comentarios, etc. 
temporalidad del flujo durante la UP y su consolidación durante la Dictadura, más allá del golpe de Estado, de la historia de los regímenes políticos y de la concepción del pluralismo.

\section{Conclusión}

Uno de los resultados más importantes de este artículo es que la historia del periodismo no sólo puede operarse a partir de los cambios políticos. Esa mirada impone rupturas y preconcibe el ejercicio de la actividad periodística desde el pluralismo, como marco de posibilidades. También reduce el rol social del periodista ante el mensaje mediático, más precisamente a las páginas editoriales de la prensa escrita. Al contrario, defendemos que es imprescindible considerar la complejidad de esa profesión, al cruce de los productos, del proceso de fabricación, de la empresa periodística, del sistema mediático, de las instituciones del campo periodístico (gremios y escuelas) y de la actitud del Estado hacia los periodistas. En otras palabras, hay que considerar las evoluciones propias de ese oficio.

Así, durante la UP, no asistimos a una regresión de la prensa hacia sus primeros pasos, que implicaban una batalla editorial monopolística y transversal a la esfera pública burguesa. La función de gatekeeper, que se instaló con la mercantilización de la prensa, la racionalización de las empresas periodísticas y la profesionalización del oficio, no se desvanece entre 1970 y 1973 . Al contrario, trata de resistir a la presión de la crisis política. Pero esa temporalidad institucional se re-articula según la prioridad de la circulación de un flujo de noticias voluminoso y acelerado. La UP es, entonces, el momento en el que, bajo la presión de los eventos cotidianos, se desajustan las rutinas profesionales para re-ordenarse según otra temporalidad. Significa que el golpe de Estado no es el resultado de la ideologización de la prensa, ni tampoco una ruptura en la historia del periodismo. Abrimos varias pistas de estudio que van en ese sentido y muestran que esas nuevas lógicas, en gérmenes en aquel entonces, podrían haberse consolidado y estabilizado durante el régimen autoritario. Queda seguir esos caminos, para evaluar las posibles evoluciones que sufrió la profesión hasta hoy.

Por último, nos parece importante relevar que ese enfoque también tiene una implicación metodológica importante para las ciencias de la comunicación y de la información como para la historia: es necesario considerar las formas y las materialidades como los valores y las formas históricas de la profesión, para analizar las fuentes de noticias mediáticas o el discurso social de los medios de comunicación. En ese sentido, este próximo paso impone dedicarse a una historia del profesionalismo periodístico, no solo desde un abordaje cultural sino también desde el neo-institucionalista histórico ${ }^{81}$.

81 En los pasos de Peter A. Hall y Rosemary C. R. Taylor., "Political Science and the Three New Institutionalisms", Political Studies, XLIV, 1996, pp. 936-957. 


\section{Bibliografía}

\section{Libros y capítulos de libro}

Juan Pablo Arancibia, Comunicación política. Fragmentos para una genealogía de la mediatización en Chile, Santiago de Chile, Universidad ARCIS, 2006.

Hannah Arendt, Los orígenes del totalitarismo, México, Taurus, 2004.

Patricio Bernedo, "La prensa escrita durante la Unidad Popular" in Claudio Rolle, 1973: La vida cotidiana en un año crucial, Santiago de Chile, Planeta, 2003, pp. 59-95.

Michel Dobry, Sociologie des crises politiques, Paris, Presses de Sciences Po, 3e édition, 2009.

Pierre Bourdieu, Sur la télévision, Paris, Raisons d'agir, 1996.

Edward Blumenthal, Julio Pinto Vallejos, El mito de la excepcionalidad chilena: un proyecto de construcción identitaria, Santiago de Chile, PUC, 2004

Robert Castel (1995), Les métamorphoses de la question sociale, Paris, Fayard.

Patricio Dooner, Periodismo y Política: la prensa de izquierda en Chile 1970-1973, ICHEH, Santiago de Chile, 1985.

Patricio Dooner, Periodismo y política: la prensa en Chile 1970-1973, Santiago de Chile, Editorial Andante, Hoy Ediciones, 1989.

Claudio Durán, El Mercurio: ideología y propaganda 1954-1994. Ensayos de interpretación bilógica y psico-histórica. Ensayo 1: propaganda de agitación en el periodo agosto 1972 - marzo 1973, Santiago de Chile, Ediciones Chileamérica-CESOC, 1995.

Antoine Faure, "La crisis mediática durante la Unidad popular (1970-1973): ¿hacia una historia discontinua del periodismo chileno?", Actas del III Congreso INCOM, Concepción, 3 y 4 de noviembre 2016b, pp. 41-55.

Joaquín Fernández, Regionalismo, liberalismo y rebelión. Copiapó en la Guerra Civil de 1859, Santiago de Chile, RIL Editores, 2016.

Herbert Gans, Deciding What's News: A Study of CBS Evening News, NBC Nightly News, Newsweek and Time, New York, Pantheon Books/London, Constable, 1980.

Manuel Gárate Chateau, La revolución capitalista de Chile (1973-2003), Editorial Universidad Alberto Hurtado, Santiago de Chile, 2012.

Franck Gaudichaud, Chili 1970-1973. Mille jours qui ébranlèrent le monde, Rennes: PUR, «Amériques », 2013.

Esteban Geoffroy, Guillermo Sunkel. Concentración Económica de los Medios de Comunicación, Santiago de Chile, LOM Ediciones, 2001.

Philippe Gottraux, «Socialisme ou Barbarie, Un itinéraire saisi par l'histoire et la sociologie », in Yves Déloye, Bernard Voutat, Faire de la science politique, Paris : Belin, 2002.

Jocelyn-Holt Alfredo, “¿Un proyecto nacional exitoso? La supuesta excepcionalidad chilena" in Francisco Colom González (ed.), Relatos de Nación. La construcción de las identidades nacionales en el mundo hispánico, Madrid, Iberoamericana/Vervuert, 2005. 
Alfredo Joignant, «Sens, masse et puissance. Dégradations cérémonielles et représentations de la puissance sous l'Unité Populaire au Chili, 1970-1973 » in Crettiez X., Sommier I., Les dimensions émotionnelles du politique. Chemins de traverse avec Philippe Braud, Rennes, PUR, 2012.

Nicolas Kaciaf, Les pages "politique ». Histoire du journalisme politique dans la presse française (1945-2006), Paris, PUR, « Res Publica », 2013.

Ian Kershaw, La dictadura nazi: problemas y perspectivas de interpretación, Buenos Aires, Siglo XXI, 2004.

Alexis Lévrier, Alice Wrona A., Matière et esprit du journal. Du Mercure galant à Twitter, Paris, Presses de l'Université Paris-Sorbonne, « Histoire de l'imprimé », 2013.

Manuel López, Cómo se trabajan las noticias, Barcelona, Paidós, 1995

Maxwell Mac Combs, Setting the Agenda: The Mass Media and Public Opinion, Cambridge, Polity Press, 2004.

Ruy Mauro Marini, El Reforma y la Revolución. Estudios sobre Chile, México D.F., ERA, 1976.

Armand Mattelart, Mass media, idéologie et mouvement révolutionnaire : Chili 1970-1973, Paris, Anthropos, 1974.

Armand Mattelart, Michèle Mattelart, Frentes culturales y Movilización de masas, Barcelona, Anagrama, 1977.

Armand Mattelart, Michèle Mattelart, De l'usage des médias en temps de crise, Paris, Alain Moreau, 1979

Carlos Ossandón B., E. Santa Cruz A., Entre las alas y el plomo. La gestación de la prensa moderna en Chile, Santiago de Chile, Universidad ARCIS, LOM Ediciones, 1998.

Jussi Parikka, What Is Media Archaeology?, Cambridge, Polity Press, 2012.

Gonzalo Piwonka Figueroa, Orígenes de la libertad de prensa en Chile, Santiago de Chile, RIL Editores, 2000.

Diego Portales, "El movimiento popular y las comunicaciones: reflexiones a partir de la experiencia chilena" en Fernando Reyes Matta, Comunicación alternativa y Búsquedas democráticas, México D. F., ILET, 1983.

Eduardo Santa Cruz A., Análisis histórico del periodismo chileno, Santiago de Chile, Nuestra América Ediciones, 1998.

Ingrid Seguel Boccara, Les passions politiques au Chili durant l'Unité populaire (1970-1973): un essai d'analyse systémique, Paris: L'Harmattan, 1997.

Jean Claude Soulages, Les mises en scènes visuelles de l'information. Etude comparée France, Espagne, Etats-Unis, Paris, Nathan, 1999.

Guillermo Sunkel, Razón y Pasión en la Prensa Popular. Un Estudio sobre Cultura Popular, Cultura de Masas y Cultura Política, Santiago de Chile, Estudios ILET, 1985.

Patricio Tupper, Allende, la cible. Des médias chiliens et de la CIA (1970-1973), Paris, Editions de L'Amandier, 2003.

Arturo Valenzuela, The Origins of Democracy: Theorical Reflections on the Chilean Case, Cambridge, Cambridge University Press, 1983.

Arturo Valenzuela, El quiebre de la democracia en Chile, Santiago de Chile, FLACSO, 1989.

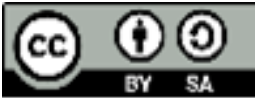


Eliseo Verón, La semiosis social. Fragmentos de una teoría de la discursividad, Barcelona, Gedisa, 1988.

\section{Artículos de revistas}

Patricio Bernedo Pinto, Eduardo Arriagada Cardini, "Los Inicios de El Mercurio de Santiago en el Epistolario de Agustín Edwards Mac Clure (1899-1905)”, Historia [online], vol. 35, 2002, pp. 1333 , <http://www.scielo.cl/scielo.php?script=sci_arttext\&pid=S0717-

\section{3\&lng=es\&nrm=iso >}

Patricio Bernedo, William Porath W., “A tres décadas del golpe: ¿Cómo contribuyó la prensa al quiebre de la democracia chilena?", Cuadernos de información, 16, 2004, p. 114-124.

Warren Breed, "Social control in the Newsroom: A Funcional Analysis", Social Forces, Vol. 33, n4, 1955, pp.326-355.

Juan Pablo Cárdenas, "Periodistas, conflictos sociales y reconciliación", Comunicación y Medios, 16, 2005, p. 112-117 <http://www.revistas.uchile.cl/index.php/RCM/article/viewFile/11567/11925>.

Robert Chaouad, "La résonance des temps", Revue internationale et stratégique, vol. 3, $\mathrm{n}^{\circ}$ 91, 2013, pp.63-67.

Patricia Fagen, "The Media in Allende's Chile", Journal of Communication, vol. 24, $\mathrm{n}^{\circ} 1$, Winter 1974, pp. 59-70

Antoine Faure, "Par temps agités. Temporalités journalistiques et crises politiques au Chili", Temporalités, $\mathrm{n}^{\circ} 23,2016 \mathrm{a}$, <http://temporalites.revues.org/3352>

Antoine Faure, Claudio Salinas, Hans Stange, "The dominance of common sense. The influence of the media system on professional practices of journalists in Chile, 1970-2000" in Puppis M., Künzler M., Jarren, O. [ed.], Media structures and media performance: state of and perspectives for communication research, Zurich, IMPZ, Series “Relation”, 2013, pp. 283-301.

Peter A. Hall y Rosemary C. R. Taylor, "Political Science and the Three New Institutionalisms", Political Studies, XLIV, 1996, pp. 936-957.

Juan Linz, "Una interpretación de los regímenes autoritario", Revista de sociología, vol. 8, 1978, pp. 11-26.

Maxwell Mac Combs M., Donald Shaw, "The agenda setting function of the mass media", Public Opinion Quarterly, vol. 36, 1972, pp. 176-187.

Armand Mattelart, Michèle Mattelart, "Ruptura y continuidad en la comunicación: puntos para una polémica", Cuadernos de Realidad Nacional (CEREN), n¹2, abril de 1972, pp. 100-144.

Armand Mattelart, Michèle Mattelart, Mabel Piccini, "Los medios de comunicación de masa. La ideología de la prensa liberal en Chile", Cuadernos de la realidad nacional, $\mathrm{n}^{\circ} 3$, marzo de 1970, Pontificia Universidad Católica de Santiago de Chile.

Michèle Mattelart, Yvonne Mignot-Lefebvre, «Chili : formation politique et lecture critique de la télévision », Tiers Monde, vol. 20, n79, 1979, pp. 523-541.

Claudia Mellado C., Mauricio Castillo, "Estructura de la asociatividad profesional en el campo periodístico: el caso de Chile", Comunicación y Sociedad, Nueva época, 2012, n 17.

Juan Rojo de la Rosa, "Manipulación de información y conflicto ideológico: Chile 1970-1973", Nueva Sociedad, julio-agosto 1976, Caracas.

Philip Schlesinger, "Newsmen and their time-machine", British Journal of Sociology, vol. 28, $\mathrm{n}^{\circ}$ 3, 
1977, p. 336-350.

Eugenio Tironi, Guillermo Sunkel, "Modernización de las comunicaciones y democratización de la política. Los medios en la transición a la democracia en Chile", Estudios Públicos, n $^{\circ}$ 52, primavera 1993, p. 215-246.

Hernán Uribe Ortega, "Los medios: armas de la guerra encubierta", en "Argentina, Cuba, Chile: realidad política y medios masivos", Comunicación y dependencia en América Latina, Universidad Nacional Autónoma de México, México, 1979.

Claudio Veliz, "Continuidades y Rupturas en la Historia Chilena: Otra Hipótesis sobre la Crisis Chilena de 1973”, Estudios Públicos, n¹2, 1983, pp. 41-64.

\section{Documentos de trabajo}

Osvaldo Corrales, Juan Sandoval. "Concentración del mercado de los medios, pluralismo y libertad de expresión”, Documentos de trabajo, CECOM, n 1, 2004, p. 67-93.

Gabriel Guzmán Riquelme, "Colegios profesionales y asociaciones gremiales durante el proceso de recuperación de la democracia en Chile", Informe de practica en el Museo de la Memoria y de los Derechos Humanos, 2012

Claudio Salinas, Hans Stange, "Rutinas periodísticas. Discusión y trayectos teóricos sobre el concepto y su estudio en la prensa chilena", Cuadernos de trabajo del ICEI, Santiago de Chile, Universidad de Chile, CECOM, 2009.

\section{Tesis}

Antoine Faure, "Dés(-)ordres journalistiques dans une crise révolutionnaire. Chroniques de l'être journalistique chilien durant l'Unité populaire (1970-1973)", bajo la dirección de Olivier Ihl (Pr. de Ciencia política), financiada por el Ministerio de Enseñanza Superior e Investigación de Francia, y defendida el 8 de diciembre de 2014 en Sciences Po Grenoble. 〈http://www.theses.fr/s97161>.

\section{Fuentes de historia oral}

Antoine Faure, "Dés(-)ordres journalistiques dans une crise révolutionnaire. Chroniques de l'être journalistique chilien durant l'Unité populaire (1970-1973)”, 2014, Tomo 2.

\section{Artículos de prensa}

$\mathrm{S} / \mathrm{N}$, "La Asamblea de los periodistas de izquierda", Punto Final, "Documentos", Suplemento de edición, $\mathrm{n}^{\circ} 129, \quad$ martes 27 de abril de <http://www.pfmemoriahistorica.org/PDFs/1971/PF_129_doc.pdf>

\section{Fuentes de testimonio escrito}

Lidia Baltra, La prensa chilena encrucijada, Santiago de Chile, LOM, CYP/CH, Colección "Ciencias humanas", 2012.

Alejandro Cabrera Ferrada, Los Vencedores del sol : reportaje a creadores de y protagonistas de los primeros dieciséis años de vida de la primera Escuela Universitaria de Periodismo de Chile 19531968, Madrid, Pays Ltda, 1994.

Carlos Silva Castro, Prensa y Periodismo en Chile (1812-1958), Santiago de Chile, Ediciones de la Universidad de Chile, 1958.

Documentos públicos 
Decreto universitario $n^{\circ} 1823$, Universidad de Chile, 14 de junio de 1954.

Ley $\mathrm{N}^{\circ} 12$ 045, Ministerio de la Justicia sobre el Colegio de periodistas de Chile, 11 de julio de 1956

Fuentes electrónicas

Toño Freire, "Con "Clarín" y "Puro Chile" temblaba "El Mercurio" y "La Tercera", Centro de estudios Miguel Enríquez - $\quad$ Archivo Chile, 2005, <http://www.archivochile.com/Experiencias/exp_popu/EXPpopulares0030.pdf>.

Fernando Muñoz, "La actualidad de los conflictos político-jurídicos del pasado (II): la Escuela Nacional Unificada", RedSeca, Revista de Actualidad Política, Social y Cultural, Santiago de Chile, 5 de septiembre 2012. 〈http://www.redseca.cl/?p=3415>

Arturo Navarro Ceardi, "La prensa chilena en termino de Cólera", 05 de noviembre 2013, <http://arturo-navarro.blogspot.fr/2013/11/la-prensa-chilena-en-tiempos-de-colera.html〉

Proyectos de investigación

Luis Ortega Martínez (dir.), "El itinerario del proyecto monetarista chileno (1952-1975)", FONDECYT No 1150819, 2015-2019. 